\title{
ASSESSING THE ENVIRONMENTAL IMPACT OF WASTEWATER TREATMENT PLANTS BY CHEMOMETRIC APPROACH
}

\author{
J. BAYO ${ }^{1}$, D. RUIZ-MARTÍNEZ ${ }^{1}$, J. CARPE ${ }^{1} \&$ J. LÓPEZ-CASTELLANOS ${ }^{2}$ \\ ${ }^{1}$ Department of Chemical and Environmental Engineering, Technical University of Cartagena, Spain \\ ${ }^{2}$ Aquambiente, Capitanes Ripoll, 8, Cartagena, Spain
}

\begin{abstract}
This paper presents the results of principal factor analysis technique (PFA) developed for a 3-year study (2010-2012) on two urban wastewater treatment plants (WWTPs) situated in Murcia, Southeast of Spain. One of them receives wastewater for a medium-sized city (WWTP1), with an important industrial area, and the other one treats only domestic wastewater from a small-sized town (WWTP2), with slightly different treatment systems between them. Process performance and operation of WWTP are carried out to ensure their compliance with legislative requirements imposed by European Union. Because high amounts of variables are daily measured, a coherent and structured approach of such a system is required to understand its inherent behavior and performance efficiency. In this sense, PFA as a chemometric technique allowed us to investigate and propose a data reduction that allowed to group water-quality variables into selected factors with common features to describe the behavior of both plants, and their similarities and differences. Four main factors were extracted for WWTP1, associated with the presence of nutrients, the ionic component, the organic load to the plant, and the efficiency of the whole process, with an explaining variance of $62.12 \%$. For WWTP2, also four main components were extracted, explaining $63.82 \%$ of the variance. These factors were pollution load to the plant, pollution output, marine intrusion, and, finally, the ionic component of water. The geochemical background composition of water in this zone and the important use of fertilizers in agriculture appeared to be two significant factors driving the results.
\end{abstract}

Keywords: chemometrics, principal factor analysis, wastewater treatment.

\section{INTRODUCTION}

A continuous monitoring of the effluent of wastewater treatment plants (WWTPs) is always required to ensure smooth operation, adjustment to prescribed legislative requirements and safety of the receiving water bodies [1]. The efficiency of the sewage treatment plant and the quality of the effluent are essential to fulfil the stringent effluent discharge standards [2], especially for nitrogen and phosphorus, both identified as the two main nutrients involved in aquatic eutrophication [3]. For this purpose, the chemometric analytical techniques applied to the study of physicochemical parameters in WWTP are widely used as a reliable assessment procedure which allows to making a simplified model of the whole plant performance, reducing the datasets to a few significant variables, factors, or components, without losing significant information [4]. In this study, principal factor analysis (PFA) has been used to investigate the complex structure underlying the huge amount of water quality variables daily processed in two WWTP, transforming them into a manageable set of uncorrelated factors that explain most of the observed variance. The final objective was to investigate a data 
reduction that allows grouping water quality variables into selected factors with common features to describe the behaviour of the plant in terms of pollution sources and treatment efficiency with a few uncorrelated components. Multivariate techniques have been widely applied to grouping water quality variables for different purposes; i.e., the composition of sewage of domestic origin [5], surface water [6,7], water quality from roof runoff [8], river watersheds [9], distribution of organic pollutants [10,11], heavy metal distribution in waters [12], new policy instruments in domestic wastewater treatment systems [13], mineral waters [14], and WWTP [15-17], among others. The multivariate statistical analysis employed for this study, besides allowing us to simplify the whole set of analyzed variables, eventually gave unexpected relationships among data, leading us to extract conclusions never expected with a more simplistic statistical approach [18].

The WWTP1 is located in Cartagena (Murcia, Spain), receiving wastewater from both urban and industrial activities. It consists of a conventional activated sludge system with a primary treatment and two parallel activated sludge reactors, serving about 2,10,000 equivalent inhabitants $\left(35,000 \mathrm{~m}^{3} \cdot \mathrm{d}^{-1}\right)$. The biological reactor consists of an anoxic tank for pre-denitrification followed by a facultative tank, both completely mixed and with a volume of $2,025 \mathrm{~m}^{3}$ each, ahead of the plug-flow aerobic reactor with a total net volume of 12,150 $\mathrm{m}^{3}$, and aerated mixed liquor return to the anoxic and facultative zones.

The WWTP2 is located in a coastal and touristic area, with minimum industrial impact, close to the Mediterranean Sea. The water line consists of screening, grit and grease removal, and secondary treatment by extended activated-sludge system, with three lines a volume of $9,721 \mathrm{~m}^{3}$ each. After the secondary clarifier, process is completed by a tertiary treatment, which consists of sedimentation, filtration, and disinfection by UV radiation. This plant is designed for 20,400 equivalent inhabitants (about $6,300 \mathrm{~m}^{3} \cdot \mathrm{d}^{-1}$ ). The WWTP1 and WWTP2 are significantly affected both for the amount and water quality entering the system, because of the changes in the population during the summer season, as it will be explained before.

\section{MATERIALS AND METHODS}

\subsection{Sample collection and dataset}

For WWTP1, daily wastewater samples were measured for 3 years and for different parameters, from the influent (after primary treatment), the activated sludge reactor, the recirculation, and the effluent of plant. For WWTP2, data for only 1 year were available.

The following water-quality parameters were included in the dataset: water flow [WF] $\left(\mathrm{m}^{3} \cdot \mathrm{d}^{-1}\right), \mathrm{pH}\left(\mathrm{pH}\right.$ units), water temperature $[\mathrm{WT}]\left({ }^{\circ} \mathrm{C}\right)$, electrical conductivity $[\mathrm{EC}]\left(\mathrm{mS} \cdot \mathrm{cm}^{-1}\right)$, turbidity [TURB] (NTU), suspended solids [SS] $\left(\mathrm{mg} \mathrm{l}^{-1}\right)$, mixed liquor suspended solids [MLSS] $\left(\mathrm{mg} \cdot \mathrm{l}^{-1}\right)$, mixed liquor volatile suspended solids [MLVSS] $\left(\mathrm{mg} \cdot \mathrm{l}^{-1}\right)$, volume of the settled sludge after 60 minutes sedimentation [V60] $\left(\mathrm{ml} \cdot \mathrm{l}^{-1}\right)$, sludge volume index [SVI] $\left(\mathrm{ml} \cdot \mathrm{g}^{-1}\right)$, chemical oxygen demand [COD] $\left(\mathrm{mg} \cdot \mathrm{l}^{-1}\right)$, biochemical oxygen demand [BOD] $\left(\mathrm{mg} \cdot \mathrm{l}^{-1}\right)$, ammonium nitrogen $\left[\mathrm{NH}_{4}-\mathrm{N}\right]\left(\mathrm{mg} \cdot \mathrm{l}^{-1}\right)$, nitrate nitrogen $\left[\mathrm{NO}_{3}-\mathrm{N}\right]\left(\mathrm{mg} \cdot \mathrm{l}^{-1}\right)$, total nitrogen $[\mathrm{TN}]$, and phosphate phosphorus $\left[\mathrm{PO}_{4}^{-} \mathrm{P}\right]\left(\mathrm{mg} \cdot \mathrm{l}^{-1}\right)$. Acronyms were used with subindexes to properly indicate influent to the biological process (I), biological reactor (BR), recirculation $(\mathrm{R})$ or effluent $(\mathrm{E})$ from the WWTP. EC was determined with a Crison GLP 32 conductimeter (Barcelona, Spain) and pH with a Crison GLP 22 pH meter (Barcelona, Spain), both calibrated by means of standard solutions. COD was determined using the Spectroquant NOVA 30 from Merck (Darmstadt, Germany), TURB with the Hach 2100N laboratory turbi- 
dimeter (Hach Company, Loveland, USA) and oxytop respirometers (WTW, Weiheim, Germany) were used for BOD analysis. All the other parameters were calculated according to the Standard Methods for the Examination of Water and Wastewater [19].

\subsection{Statistical analysis}

Statistical analysis was carried out using Statistical Package for the Social Sciences (SPSS for Windows 22.0). Pearson's correlation coefficient $(r)$ was computed between different parameters to determine the extent to which values of both parameters were correlated. Tukey-Kramer method was the multiple comparisons procedure used for the simultaneous estimation of pairwise differences of means in one-way ANOVA, and F-Snedecor values were used for its fitting performance.

The PFA resulted in a number of factors smaller than the initial set of variables; the first factor explains the largest part of the variance and the others represent successively smaller portions. To verify the factors' quality, three criteria were followed: the explained variance of each individual factor must be greater than $5 \%$, the accumulated portion of explained variance must be higher than $70 \%$, and the results should be represented in a simple rotated matrix structure to facilitate interpretation [20]. For this purpose, varimax orthogonal rotation with Kaiser normalization was used as the rotation method, preferable to more complicated oblique rotation methods [21].

The PFA reported different elements as a result: correlation matrix, Kaiser-Meyer-Olkin (KMO) test of sampling adequacy, used to study the fit degree of the data to factor analysis, and Bartlett's test of sphericity, to examine the null hypothesis that the resulting correlation matrix is an identity matrix. Besides these parameters, total explained variance, sedimentation graphic, and the rotated solution were obtained. Finally, the sedimentation graphic allowed us to choose the number of factors to be extracted; i.e., those with eigenvalues greater than one according to the Kaiser criteria.

\section{RESULTS AND DISCUSSION}

\subsection{General considerations}

Table 1 depicts the KMO and Barlett's tests for both WWTP. In both cases, we can reject the null hypothesis that the correlation matrix is an identity matrix, accepting a clear correlation between response categories and appropriateness of the selected model, with less data than the original. Also in both dataset, the KMO test indicated a middling sampling adequacy (between 0.700 and 0.790), according to Kaiser's classification [22], which means that it is acceptable to use the PFA technique. For WWTP1, 21 out of 32 attributes satisfied the 0.4 cross-factor loading threshold in the varimax rotated matrix, and 16 attributes for WWTP2.

As presented in Table 2, six factors were extracted for WWTP1 with eigenvalues greater than one, also known as Kaiser's rule [23], describing $72.80 \%$ of the total variance of the dataset. Each factor represents a variable in the model, although it is comprised of a linear combination of different attributes. The first factor (PF1) accounted for $25.93 \%$ of the total variance, the second factor (PF2) accounted for $18.15 \%$ of the total variance, the third factor (PF3) accounted for $10.93 \%$ of the total variance, the fourth factor (PF4) accounted for $7.10 \%$ of the total variance, the fifth factor (PF5) accounted for 5.85\%, and the sixth factor (PF6) accounted for $4.83 \%$ of the total variance. Then, the reduction of dataset dimensionality was from 21 to 6 , this is $71.43 \%$, losing about $30 \%$ of information. 
Table 1: KMO and Barlett's tests results for WWTP1 and WWTP2.

\begin{tabular}{cccc}
\hline \multicolumn{5}{c}{ WWTP1 } \\
\hline Kaiser-Meyer-Olkin value & \multicolumn{3}{c}{ Barlett's test of sphericity } \\
\hline 0.751 & Chi-square approx. & d.f. & Sig. \\
& $2,054.423$ & 210 & $p<0.001$ \\
\hline \multicolumn{5}{c}{ WWTP2 } \\
\hline Kaiser-Meyer-Olkin value & \multicolumn{3}{c}{ Barlett's test of sphericity } \\
\hline 0.763 & Chi-square approx. & d.f. & Sig. \\
& $1,668.507$ & 136 & $p<0.001$ \\
\hline
\end{tabular}

Table 2: Component and total explained variance for WWTP1 and WWTP2 after varimax orthogonal rotation ${ }^{\mathrm{a}}$.

\begin{tabular}{llll}
\hline & & WWTP1 \\
\hline Component & & & Cumulative \\
(Factor) & Eigenvalue & Initial variance(\%) & variance (\%) \\
\hline PF1 & 5.446 & 25.933 & 25.933 \\
PF2 & 3.812 & 18.154 & 44.087 \\
PF3 & 2.296 & 10.932 & 55.019 \\
PF4 & 1.491 & 7.101 & 62.120 \\
PF5 & 1.229 & 5.851 & 67.971 \\
PF6 & 1.014 & 4.827 & 72.798 \\
\hline & & WWTP2 & \\
\hline & & & Cumulative variance \\
Component (Factor) & Eigenvalue & Initial variance(\%) & $(\%)$ \\
\hline PF1 & 5.178 & 30.457 & 30.457 \\
PF2 & 2.468 & 14.516 & 44.972 \\
PF3 & 1.782 & 10.480 & 55.452 \\
PF4 & 1.423 & 8.370 & 63.822 \\
PF5 & 1.258 & 7.402 & 71.224 \\
\hline
\end{tabular}

In a similar way, five factors were extracted for WWTP2 with eigenvalues greater than one, describing $71.22 \%$ of the total variance of the dataset. The first factor (PF1) accounted for $30.46 \%$ of the total variance, the second factor (PF2) accounted for $14.52 \%$ of the total variance, the third factor (PF3) accounted for $10.48 \%$ of the total variance, the fourth factor (PF4) accounted for $8.37 \%$ of the total variance, and the fifth factor (PF5) accounted for 
$7.40 \%$. In this case, the reduction of dataset dimensionality was from 28 initial variables to 5 , this is $82.14 \%$, losing also about $30 \%$ of information.

\subsection{Principal factor analysis for WWTP1}

Once factors were extracted, there is a need for their interpretation. The first factor (PF1) was characterized by a clear influence of nutrient pollution, as it was mainly affected by nitrogen and phosphorus compounds; therefore, it could be labelled as the "nutrient factor", increased during winter and spring $(F=5.112, p<0.01)$. Acosta et al. [24] have reported a increase in the application of fertilizers during these seasons. The second factor (PF2) represented the inorganic or ionic component of the model, mainly represented by the water electrical conductivity and water temperature. The electrical conductivity proved to be higher for the summer than for the other three seasons, which could be explained by an easier evaporation of water due to an increase on temperature and sun irradiance, significantly different from the other seasons with increased precipitations, leading to a general diluting effect [25]. The third PF3 was mainly related to the organic load of wastewater; including suspended solids (0.648), chemical (0.879) and biochemical (0.839) oxygen demand in the influent. For that reason, positive scores on PF3 were mainly observed for samples collected in winter, spring, and autumn for the three studied years, where the population within the city is at its height, decreasing during the summer season In contrast, the second factor displayed the positive score during the spring and summer periods, showing the geochemical background component of our waters. The fourth factor received high loadings from suspended solids in the effluent, chemical oxygen demand, and biochemical oxygen demand, all of them in the effluent of the WWTP1. Because the positive loading of these three variables in the effluent, this factor may be considered as a measure of the WWTP1 performance efficiency, being higher for winter and spring, when both the organic and nutrient load are increased. The fifth factor and sixth factor were eliminated for the analysis, as they proved to display only one water quality parameter each one. A similar decision has been reported by other authors [20].

\subsection{Principal factor analysis for WWTP2}

Table 3 depicts loadings for each factor or component after varimax rotation for WWTP2. Again, the first factor (PF1) was characterized by the highest number of attributes loading on a single factor (six). The water-quality parameters loading on this factor were V60 (0.732), SS (0.904), BOD (0.911), COD (0.908), TN (0.735), and phosphate (0.934), all of them in the influent. Because this result, PF1 could be associated with the pollution input to the WWTP2, both organic and inorganic, and could perfectly represent the influent to the sewage plant. As depicted in Fig. 1, it is worth noting that its value increases during summer season, due to the location of WWTP2 in a coastal and touristic zone.

The second component (PF2) accounts for $14.52 \%$ of explained variance and includes [SS] ${ }_{\mathrm{E}}(0.718),[\mathrm{BOD}]_{\mathrm{E}}(0.728)$, and $[\mathrm{TN}]_{\mathrm{E}}(0.613)$. These weights give the PF2 the role of effluent, or the pollution output of WWTP2. As in PF4 for WWTP1, the positive loading of these three variables within the PF2 for WWTP2 would indicate a measure of the performance efficiency. As presented in Fig. 1, PF2 values by season are always under 0.0 score, except for autumn. This could be due to heavy rains and intense storms taking place in our Mediterranean area during that season, producing strong water runoffs loaded with particulate matter and water pollutants, including nutrients and fertilizers that could reach the WWTP2. 
Table 3: Rotated component matrix with factor loadings (>0.4) for WWTP2.

\begin{tabular}{|c|c|c|c|c|c|}
\hline \multirow[b]{2}{*}{ Attribute } & \multicolumn{5}{|c|}{ Factor (component) } \\
\hline & PF1 & PF2 & PF3 & PF4 & PF5 \\
\hline [WF] & & & -0.434 & & \\
\hline$[\mathrm{pH}]_{\mathrm{I}}$ & & & 0.899 & & \\
\hline$[\mathrm{pH}]_{\mathrm{E}}$ & & & 0.861 & & \\
\hline$[E C]_{I}$ & & & & 0.851 & \\
\hline$[\mathrm{EC}]_{\mathrm{E}}$ & & & & 0.828 & \\
\hline [V60] & 0.732 & & & & \\
\hline [TURB] & & & & & 0.812 \\
\hline$[\mathrm{SS}]_{\mathrm{I}}$ & 0.904 & & & & \\
\hline$[S S]_{E}$ & & 0.718 & & & \\
\hline$[\mathrm{BOD}]_{\mathrm{I}}$ & 0.911 & & & & \\
\hline$[\mathrm{BOD}]_{\mathrm{E}}$ & & 0.728 & & & \\
\hline$[\mathrm{COD}]_{\mathrm{I}}$ & 0.908 & & & & \\
\hline$[\mathrm{COD}]_{\mathrm{E}}$ & & & & & 0.726 \\
\hline$[\mathrm{TN}]_{\mathrm{I}}$ & 0.735 & & & & \\
\hline$[\mathrm{TN}]_{\mathrm{E}}$ & & 0.613 & & & \\
\hline$\left[\mathrm{PO}_{4}-\mathrm{P}\right]_{\mathrm{I}}$ & 0.934 & & & & \\
\hline$[\mathrm{PO} 4-\mathrm{P}]_{\mathrm{E}}$ & 0.934 & & & 0.487 & \\
\hline
\end{tabular}

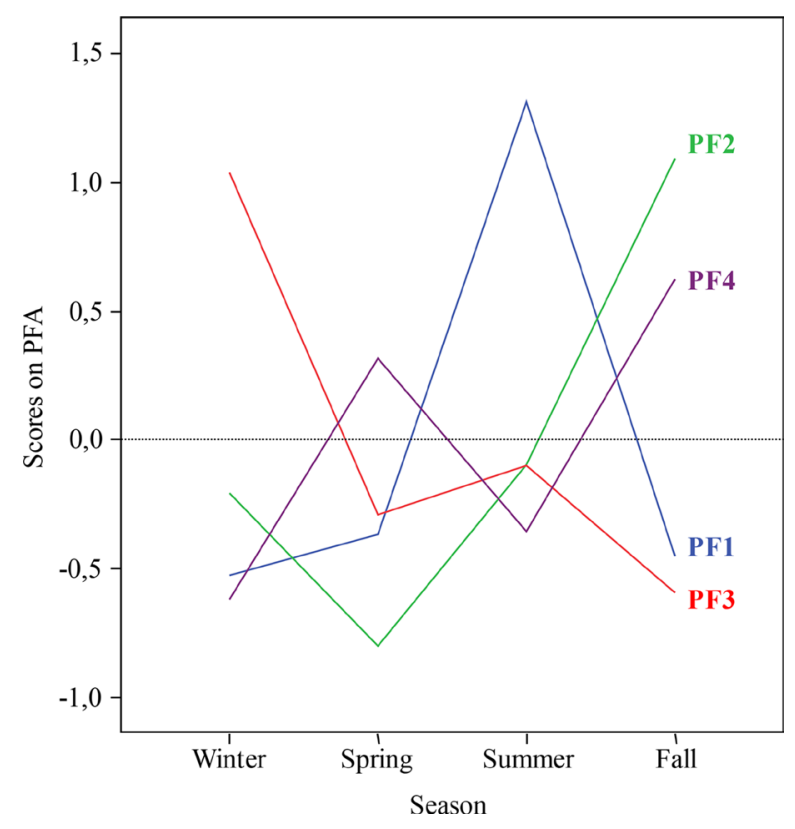

Figure 1: Temporal patterns for first four components by season in WWTP2. 
The third extracted factor $(\mathrm{PF} 3)$ are involved such variables as $[\mathrm{pH}]_{\mathrm{I}}(0.899)$ and $[\mathrm{pH}]_{\mathrm{E}}$ $(0.861)$, and with a lower weight $[\mathrm{WF}](-0.434)$. This factor increases in winter, being negative the rest of the seasons, when tourism increases in that area. For that reason, it could be related to marine intrusion in the sewage system. During wintertime, the discharge to the sewage system is the lowest compared with the other three seasons; this fact would explain that marine intrusion would look highlighted during winter, with a rise of $\mathrm{pH}$ because of the basic character of seawater. The rest of the year, the higher water flow would cushion this effect.

The fourth factor (PF4) explained $8.37 \%$ of the variance in the dataset (Table 2), receiving loadings from two water-quality parameters: EC, both in the influent $(0.851)$ and the effluent (0.828), and phosphate in the effluent (0.487). This factor could represent the inorganic or ionic component of the model, displaying its higher values during spring and fall. As in PF2 for WWTP1, its ascent during spring is due to the rise of temperature in this period related to winter, allowing higher water evaporation. Although this pattern should continue in summer, the increase in population, with the highest water flow for WWTP2, would mask this factor. The temperature stays high in this latitude during autumn, although the touristic population decreases, rising PF4 again. Beside this, the previously mentioned storm water runoff during autumn would explain the increase on phosphorus values. The fifth factor (PF5) demonstrated $7.40 \%$ of the variance in the data, with only two variables represented; i.e., TURB and COD in the effluent. As indicated by other authors [26], this factor could be ignored. Exclusion of this PF5 for WWTP2 meant the reduction in the explained variance from $71.22 \%$ down to $63.82 \%$ of the dataset. Similar results have been previously reported; Zhang et al. [7] reported an explained variance of $58.79 \%$ for four factors controlling the water quality of the Xiangjiang River, and Vialle et al. [8] explained, with three components, a $60.00 \%$ of the total variance of their dataset for water quality monitoring of roof runoff.

\section{CONCLUSIONS}

This study used a different chemometric techniques, PFA, to identify the inherent structure of a water quality dataset, containing physical and chemical parameters from two different WWTP. One of them receives WWTP1, with an important industrial area, and the other one treats only domestic WWTP2 situated near the coast. Four main factors were extracted for both of them, although with slightly different interpretations. WWTP2 displayed a marine intrusion factor because of its proximity to the sea, being higher during winter time, when the population in the coast decreases. However, WWTP1 presented a specific factor dealing with nutrients, because its proximity to agricultural areas. It is interesting to note that both of them shared an ionic component, due to the geochemical background composition of water in our region.

\section{REFERENCES}

[1] Tchobanoglous, V.G., Burton, F.L. \& David, H. (eds), Wastewater Engineering: Treatment and Reuse, 4th edn., McGraw-Hill: New York, 2003.

[2] Council Directive 91/271/EEC of 21 May 1991 concerning urban waste water treatment (amended by Directive 98/15/EC). Official Journal of European Union L135/40 (30 of May 1991).

[3] Zuthi, M.F.R., Guo, W.S., Ngo, H.H., Nghiem, L.D. \& Hai, F.I., Review: Enhanced biological phosphorus removal and its modeling for the activated sludge and membrane bioreactor processes. Bioresource Technology, 139, 363-374, 2013. http://dx.doi.org/10.1016/j.biortech.2013.04.038 
[4] Noori, R., Karbassi, A. \& Sabahi, M.S., Evaluation of PCA and gamma test techniques on ANN operation for weekly solid waste prediction. Journal of Environmental Management, 91, 767-771, 2010.

http://dx.doi.org/10.1016/j.jenvman.2009.10.007

[5] Singh, K.P., Malik, A., Mohan, D., Sinha, S. \& Singh, V.K., Chemometric data analysis of pollutants in wastewater: a case study. Analitycal Chimica Acta, 532, 15-25, 2005. http://dx.doi.org/10.1016/j.aca.2004.10.043

[6] Hussain, M., Ahmed, S.M. \& Abderrahman, W., Cluster analysis and quality assessment of logged water at an irrigation project, eastern Saudi Arabia. Journal of Environmental Management, 86, 297-307, 2008. http://dx.doi.org/10.1016/j.jenvman.2006.12.007

[7] Zhang, Z., Tao, F., Du, J., Shi, P., Yu, D., Meng, Y. \& Sun, Y., Surface water quality and its control in a river with intensive human impacts-a case study of the Xiangjiang River, China. Journal of Environmental Management, 91, 2483-2490, 2010. http://dx.doi.org/10.1016/j.jenvman.2010.07.002

[8] Vialle, C., Sablayrolles, C., Lovera, M., Jacob, S., Huau, M.C. \& Montrejaud-Vignoles, M., Monitoring of water quality from roof runoff: Interpretation using multivariate analysis. Water Research, 45, 3765-3775, 2011. http://dx.doi.org/10.1016/j.watres.2011.04.029

[9] Olsen, R.L., Chappell, R.W. \& Loftis, J.C., Water quality sample collection, data treatment and results presentation for principal components analysis-literature review and Illinois River watershed case study. Water Research, 46, 3110-3122, 2012. http://dx.doi.org/10.1016/j.watres.2012.03.028

[10] Saba, T. \& Su, S., Tracking polychlorinated biphenyls (PCBs) congener patterns in Newbark Bay surface sediments using principal component analysis (PCA) and positive matrix factorization (PMF). Journal of Hazardous Materials, 260, 634-643, 2013. http://dx.doi.org/10.1016/j.jhazmat.2013.05.046

[11] Zhang, W., Zhang, Y., Taniyasu, S., Yeung, L.W.Y., Lam, P.K.S., Wang, J., Li, X., Yamashita, N. \& Dai, J., Distribution and fate of perfluoroalkyl substances in municipal wastewater treatment plants in economically developed areas of China. Environmental Pollution, 176, 10-17, 2013. http://dx.doi.org/10.1016/j.envpol.2012.12.019

[12] Bingöl, D., Ay, Ü., Bozbas, S.K. \& Uzgören, N., Chemometric evaluation of the heavy metals distribution in waters from the Dilovasi region in Kocaeli, Turkey. Marine Pollution Bulletin, 68, 134-139, 2013. http://dx.doi.org/10.1016/j.marpolbul.2012.12.006

[13] Naughton, O. \& Hynds, P.D., Public awareness, behaviours and attitudes towards domestic wastewater treatment systems in the Republic of Ireland. Journal of Hydrology, 518, 108-119, 2014. http://dx.doi.org/10.1016/j.jhydrol.2013.08.049

[14] Astel, A., Michalski, R., Lyko, A., Jablonska-Czapla, M., Bigus, K., Szopa, S. \& Kwiecinska, A., Characterization of bottled mineral waters marketed in Poland using hierarchical cluster analysis. Journal of Geochemical Exploration, 143, 136-145, 2014. http://dx.doi.org/10.1016/j.gexplo.2014.04.002

[15] Aguado, D. \& Rosen, C., Multivariate statistical monitoring of continuous wastewater treatment plants. Engineering Applications of Artificial Intelligence, 21, 1080-1091, 2008. http://dx.doi.org/10.1016/j.engappai.2007.08.004 
[16] Ouali, A., Azri, C., Medhioub, K. \& Ghrabi, A., Descriptive and multivariate analysis of the physico-chemical and biological parameters of Sfax wastewater treatment plant. Desalination, 246, 496-505, 2009. http://dx.doi.org/10.1016/j.desal.2008.04.058

[17] Platikanov, S., Rodriguez-Mozaz, S., Huerta, B., Barceló, D., Cros, J., Batle, M., Poch, G. \& Tauler, R., Chemometrics quality assessment of wastewater treatment plant effluents using physicochemical parameters and UV absorption measurements. Journal of Environmental Management, 140, 33-44, 2014.

http://dx.doi.org/10.1016/j.jenvman.2014.03.006

[18] Johnson, R.A. \& Wichern, D.W., Applied Multivariate Statistical Analysis, 6th edn., Pearson: Mexico, 2008.

[19] Rice, E.W., Baird, R.D., Eaton, A.D. \& Clesceri, L.S. (eds.), APHA, Standard Methods for the Examination of Water and Wastewater, 22nd edn., American Public Health Association, American Water Works Association \& Water Environment Federation: Washington D.C., 2012.

[20] Gazzaz, N.M., Yusoff, M.K., Ramli, M.F., Aris, A.Z. \& Juahir, H., Characterization of spatial patterns in river water quality using chemometric pattern recognition techniques. Marine Pollution Bulletin, 64, 688-698, 2012. http://dx.doi.org/10.1016/j.marpolbul.2012.01.032

[21] Reimann, C., Filzmoser, P. \& Garrett, R.G., Factor analysis applied to regional geochemical data: problems and possibilities. Applied Geochemistry, 17, 185-206, 2002. http://dx.doi.org/10.1016/S0883-2927(01)00066-X

[22] Kaiser, H.F., An index of factorial simplicity. Psychometrika, 39, 31-36, 1974. http://dx.doi.org/10.1007/BF02291575

[23] Kaiser, H.F., The application of electronic computers to factor analysis. Education and Psychological Measurement, 20, 141-151, 1960. http://dx.doi.org/10.1177/001316446002000116

[24] Acosta, J.A., Faz, A., Jansen, B., Kalbitz, K. \& Martínez-Martínez, S., Assessment of salinity status in intensively cultivated soils under semiarid climate, Murcia, SE Spain. Journal of Arid Environments, 75, 1056-1066, 2011. http://dx.doi.org/10.1016/j.jaridenv.2011.05.006

[25] Bayo, J., López-Castellanos, J., Martínez-García, R., Alcolea, A. \& Lardín, C., Hydrocyclone as a cleaning device for anaerobic sludge digesters in a wastewater treatment plant. Journal of Cleaner Production, 87, 550-557, 2015. http://dx.doi.org/10.1016/j.jclepro.2014.10.064

[26] Osborne, J.W. \& Costello, A.B., Best practices in exploratory factor analysis: Four recommendations for getting the most from your analysis. Pan-Pacific Management Review, 12(2), 131-146, 2009. 